\title{
Evaluation of pay-by-use (PBU) domestic waste charging systems in Ireland
}

\author{
A. O’Callaghan-Platt ${ }^{1}$, T. Coakley ${ }^{2}$ \& C. Gibson ${ }^{2}$ \\ ${ }^{I} O$ 'Callaghan-Platt Environmental Solutions, Ireland \\ ${ }^{2}$ The Clean Technology Centre, Cork Institute of Technology, Ireland
}

\begin{abstract}
Irish waste collectors were advised by the Department of Environment, Heritage and Local Government to adopt pay-by-use (PBU) domestic waste charges from $1^{\text {st }}$ January 2005. The measure was taken to combat the rising volumes of waste produced nationally and to apply the polluter pays principle to waste charges, in line with EU waste principles and sustainability objectives. The PBU charges have been adopted by waste collectors nationwide; however these charges have been implemented in different forms across the country with several different PBU systems (weight, tag, and differential bin size systems) used by waste collectors. In order to optimise PBU to ensure achievement of nationally desired waste management outcomes research into the impacts each PBU system was undertaken. The study evaluated the components of each PBU system in terms of their impacts upon waste disposal, recycling, and, in particular, source reduction in order to determine the most environmentally effective system. The research into the impacts of PBU systems on the environment found that in Ireland weight-based PBU charges are marginally more environmentally effective than tag-based charges and differential bin size charges in terms of residual, recycling, and total waste levels.
\end{abstract}

Keywords: domestic waste, waste charges, economic instruments in Ireland, pay-as-you-throw, total waste, domestic recycling.

\section{Introduction}

"As a matter of equity and in order to directly incentivise waste reduction, the level of waste charges should vary according to usage" (DoEHLG [1]). This statement in the 1998 Department of Environment policy document 'Changing 
Our Ways' (DoEHLG [1]) advocated the adoption of pay-by-use (PBU) charges in the Irish domestic waste sector to attain the policy objective, outlined in the 1998 policy document 'An Action Plan for the Millennium', of implementing the internationally recognised waste hierarchy in Ireland (DoEHLG [1, 2]). In theory PBU charges, also known as pay-as-you-throw or unit-based charges, send a more accurate pricing signal for generation of refuse and therefore encourage householders to reduce waste, recycle more and change waste management habits (see for example Linderhof et al [3] and Nestor and Podolsky [4]). In 2004 local authorities were advised that all domestic waste charges should be within a PBU system from $1^{\text {st }}$ January 2005, with permits for private waste collectors containing the new requirements when their current permit is up for renewal by the local authority (DoEHLG [5]). The driving forces behind the move to PBU domestic waste charges can be found at both a national and an EU level.

Charging for domestic solid waste collection was abolished in 1977, subsequent to this Ireland's local authorities found themselves increasingly short of funds (Lawlor and Scott [6]). In 1983 national legislation was passed allowing the authorities to once again levy charges on households for waste collection and disposal services supplied. Despite this, charging was not widespread for many years and the local authorities that chose to levy charges at a flat rate waste collection fee, with householders paying the same charge regardless of the amount of refuse put out for collection. Under a flat fee for waste collection households face a zero marginal cost to producing more waste and have no incentive to reduce the production of waste or increase the recycling of waste. In 1997 and 1998 a series of government policy documents on waste management (DoEHLG $[1,7,8]$ ) focused on the need for changes to be made in the waste management sector and of the necessity for a considerable reduction in the amount of waste going to landfill. From 2002 to 2004 policy statements on waste focused on introducing economic instruments in line with the polluter pays principle to reduce the rising volume of household waste in Ireland (DoEHLG [9-11]).

The changes in attitude to domestic waste management expressed in Ireland reflected the movement by the EU to tackle the increasing production of waste. All EU waste management regulations are based on the key principles laid down by the European Union in the 1975 Waste Framework Directive (EEC [12]). These values included the Polluter Pays Principle (the principle that those causing pollution should meet the costs to which it gives rise). In more recent years the 1997 EU Strategy for Waste Management (EEC [13]) asserts the value of economic instruments as a method of applying the Polluter Pays Principle in waste management and outlined a waste management hierarchy for EU member states. The Waste Hierarchy places landfill as the least desirable method of waste disposal and on this basis all Irish waste policy is focused on redirecting waste streams further up the Hierarchy, to methods such as prevention and recycling. Together the Polluter Pays Principle and the Waste Hierarchy advocate a diversion of waste from landfill using methods that charge producers of waste according to the amount of waste they create. To this end in Ireland on January $1^{\text {st }} 2005$ flat rate waste collection charges were required to be replaced with PBU 
domestic waste collection charges with the aim of reducing the amount of waste produced and sent to landfill by householders through applying the polluter pays principle.

Research into the impact of PBU domestic waste charges in Ireland (O'Callaghan-Platt and Davies [14]) found that PBU charges have reduced domestic waste for landfill presentation rates, a finding that is consistent with results experienced in other countries/regions as reported in the international literature on PBU. However, the degree to which presentation rates were reduced in Ireland was found to be notably lower than reductions identified elsewhere. O'Callaghan-Platt and Davies [14] found a 3.5\% decrease nationally in waste presentation rates overall from 2003 to 2005 in local authorities with PBU charges. How does this percentage decrease compare to reductions elsewhere in the world and to reductions seen in pilot studies in Ireland? The majority of studies of pay-by-use charging conclude that they successfully decrease the amount of refuse collected in both the long and short term irrespective of whether the location was urban, rural or suburban (Linderhof et al. [3]; Nestor and Podolsky [4]; Dijkgraaf and Gradus [15]; Sterner and Bartlings [16]). However the extent of non-recyclable waste reduction varies widely amongst these studies with the cases recording reductions of between 6-56\% (Linderhof et al. [3]; Dijkgraaf and Gradus [15]; Sterner and Bartlings [16]; Bauer and Miranda [17]; Dunne [18, 19]; Fullerton and Kinnaman [20]; Kinnaman and Fullerton [21]; Miranda and Aldy [22]; Skumatz [23]). Examination of the literature reveals that regions implementing weight-based systems experienced a larger decrease in waste to landfill than regions implementing volume-based systems. These findings are consistent with the predictions of theoretical pay-byuse models that conclude that weight-based systems are the most effective in effecting change (see for example, Dijgkraaf and Gradus [15]; Fullerton and Kinnaman [20]).

Although all waste collectors in Ireland were required to move to a PBU form of waste charging by the $1^{\text {st }}$ January 2005 , no requirements were made on the type of PBU system to be implemented by collectors, or the charges to be set within the selected system. Waste collectors were at liberty to select all aspects of their system provided that it could be considered PBU. The 2004 press release announcing the introduction of PBU charges stated "The precise charging mechanism will be decided at local level where local circumstances can be best taken into account. However, from $1^{\text {st }}$ January 2005, whatever system is introduced will have to respect the overarching principle of charging on the base of usage" (DOEHLG [5]). Advice on choice of PBU system was not given at a national level, leaving waste collectors to gather information elsewhere when selecting a PBU charging system. This has resulted in the situation where several different systems of collection are currently operating in Ireland. The mixed use of PBU systems currently in place may be hindering the potential for positive changes in domestic waste management behaviours on a national level.

In order to optimise PBU to ensure achievement of nationally desired waste management outcomes further research into the impacts of the various 
components of each PBU system was undertaken, the remainder of this paper will outline this research.

\section{Methodology}

In the study of potential optimised PBU systems for Ireland, the project required information from Irish waste collectors (private and public) implementing payby-use (PBU) charges and from householders, to determine their experiences of these systems.

In order to gather these data a waste collector survey, an examination of private waste collector Annual Environmental Reports (AERs), and a household survey were undertaken.

There were two main aims of the waste collector survey and AER analysis:

- $\quad$ to analyse the implementation of PBU in Ireland, and

- to examine the impact of PBU systems on the environment.

With this information, a picture of PBU implementation in Ireland were developed, outlining which systems are most and least common, trends in their usage, the range of charges issued to householders within each system, the availability of kerbside recycling services, the frequency of bin collections etc.

In addition, the figures allowed for analysis of the impact of PBU systems on rates of waste disposal, recycling and on total waste levels (considering, for example, possible reductions in waste arising due to charging systems).

Using data sets gathered from all 15 local authorities that collect domestic waste and AERs from private collectors the three forms of PBU used by domestic waste collectors in Ireland, tag-based systems, weight-based systems and differential bin size charges, were examined to determine their implementation, impact upon the environment, and impact upon waste collectors.

\subsection{Gathering data on public waste collectors}

A survey was developed for the local authorities that collect domestic waste. The survey gathered the following data:

- The PBU system used.

- Number of households served.

- Tonnes of residual waste collected.

- Tonnes of recyclable waste collected.

The survey was sent out to the 15 local authorities that collect domestic waste, all 15 completed the survey.

\subsection{Gathering data on private waste collectors}

In order to gather data from private waste collectors the research team gathered 2008 Annual Environmental Reports (AERs) from local authorities for private domestic waste collectors operating within their functional area. AERs were provided by 18 local authorities, resulting in 79 AERs across three of the four 
provinces, representing both urban and rural communities, and companies of different sizes.

The following data was provided in the AER for each collector:

- Number of households served

- Tonnes of residual waste collected

- Tonnes of recyclable waste collected

In addition the local authority was requested to provide details of the PBU system/s used by each collector.

\subsection{Selecting data sets for analysis}

Of the data sets gathered some were discounted from the analysis for following reasons:

- Some did not provide details on the PBU system used (and had no name provided, thus preventing follow up queries)

- Some companies use more than one PBU system and their waste collection figures are not separated according to the systems used.

- Furthermore each survey response/AER was assessed to determine the validity of the figures on a per-household-level. Several data sets were removed from the analysis following this assessment. For example, the calculation from one data set led to a per household annual recycling level of $2 \mathrm{~kg}-$ this is clearly erroneous. In this case the recycling figure may be low owing to an incorrect assumption that all households with a residual waste collection by the operator also had and used a recycling collection. The total number of households served by a collector is provided in the AERs but information on how many of these households also have a recycling service is not always provided. For reasons such as this several data sets could not be included in the analysis.

- When assessing the validity of data it was noticed that per household figures provided by some tag-a-bag collectors varied widely from per household figures provided by collectors using other PBU systems. None of the tag-a-bag collectors use an annual service charge and thus these collectors do not have an accurate knowledge of the number of households served weekly by their collection service; any household in their collection area may buy one of the collector's waste bags in a local shop and present it for collection. Without accurate household numbers many of the figures for residual and recycling waste were abnormal at a household level. For example, calculations with the data provided by taga-bag collectors led to figures such as $2 \mathrm{~kg}$ of recycling/household/year and $3,300 \mathrm{~kg}$ of residual waste/household/year. Figures such as these were clearly inaccurate and on this basis figures for tag-a-bag collectors were removed from the final analysis and are not included in the findings presented for tag-based systems in any of the following sections.

Following these deductions usable data was available for 56 private collector data sets. 
All 15 local authorities that collect domestic waste provided data for the study. However one of these local authorities has three separate waste collection areas which gather data separately, resulting in a total of 17 local authority data sets. Of these 17 local authority data sets:

- One uses a tag-a-bag system and was omitted from the analysis (since again the number of households served is impossible to know).

- One tag-a-bin collector was omitted as the data provided were considered erroneous.

Following these deductions usable data was available for 15 local authority data sets.

When local authority and private waste collector usable data were combined it resulted in 71 data sets for analysis.

\section{Results}

When analyzing the findings of the waste collector survey local authority and private waste collector data was combined, this resulted in 71 usable data sets for analysis.

\subsection{The implementation of PBU in Ireland}

Of these 71 data sets:

- $26(37 \%)$ waste collectors use a differential bin size system

- $23(32 \%)$ waste collectors use a tag-based system

- $22(31 \%)$ waste collectors use a weight-based system

The differential bin size charging system charges households a set fee based on the residual bin size they select to use; the annual charge for a $240 \mathrm{~L}$ residual bin will be more expensive than the charge for a $120 \mathrm{~L}$ residual bin. Once the annual charge is paid the householder can present their bin as often as they require without incurring any additional cost.

The tag-based system grouping encompasses three PBU systems: tag-a-bin, pay-per-lift and tag-a-bag.

- The tag-a-bin system involves the purchase of tags that are then attached to the municipal solid waste (MSW) bin; bins without a tag are not collected. Bin tags vary in price according to the size of the bin used by the householder, with tags for larger bins costing more than tags for smaller bins.

- In some cases bin tags are also required for the dry recyclable fraction (DRF) and separated organic fraction bins. However the cost of tags for these bins is lower than for MSW bin tags in order to incentivise waste diversion from landfill.

- The pay-per-lift system involves a chipped bin recording the number of times it is lifted for collection and the household then receiving a regular bill charging them per bin lift.

- Finally the tag-a-bag system involves the purchase of a tag or sticker that is attached to a bag of waste allowing it to be collected. 
All three systems work on the same principle: the household pays directly for the volume of waste they present, whether within a bin or a bag. Therefore these three systems have been grouped together under the category of 'tag-based PBU charges' for the purposes of the analysis. However the tag-a-bag system was subsequently removed from the final figures for the reasons listed in section 2.3.

The weight-based system grouping includes three pay-by-weight systems currently used in Ireland.

- The 'per kilogramme' system involves the use of a charge per kilogramme $(\mathrm{kg})$ of MSW placed out for collection in wheelie bins, in addition to an annual flat rate service charge. When an MSW bin is lifted the weight of the bin is recorded and the householder is later issued with a bill which includes a portion of the service charge and the charge for the weight of waste presented by the householders.

- The 'banded' weight-based system uses several weight brackets that an annual bin weight may fall within, with a different price for each weight bracket.

- The 'average weight' weight-based system uses a calculated average household waste presentation rate (commonly $800 \mathrm{~kg}$ per year), if a household produces less weight than this average they receive a reduction on their next annual bill and if a household produces more weight than this average they are billed for the additional weight.

When examining the implementation of the charges a disparity of costs/charge applied, involving up front service charges, bin costs, tag costs etc. was noted throughout Ireland. However there did not seem to be any major pattern of overall amounts on total waste collected, or disposal to recovery ratios among the different amounts of charges applied.

\subsection{The impact of PBU systems on the environment}

The research into the impacts of PBU systems on the environment found that in Ireland weight-based PBU charges are more effective than tag-based and differential bin size charges in reducing the negative impacts of domestic waste. These charges have prompted householders to divert waste from their residual waste bin more effectively than tag-based or differential bin size charges. Households using a weight-based charging system have a higher rate of recycling, and weight-based charges have been found to have lower average total waste levels, as presented at the kerbside, than either tag-based or differential bin size charges.

\subsubsection{Disposal}

On average householders in weight-based areas placed $74 \%$ of their total presented waste into the residual waste bin. In comparison the tag-based householders placed, on average, $77 \%$ of waste in their residual waste bin, and the differential bin size householders placed $79 \%$ in this bin. 


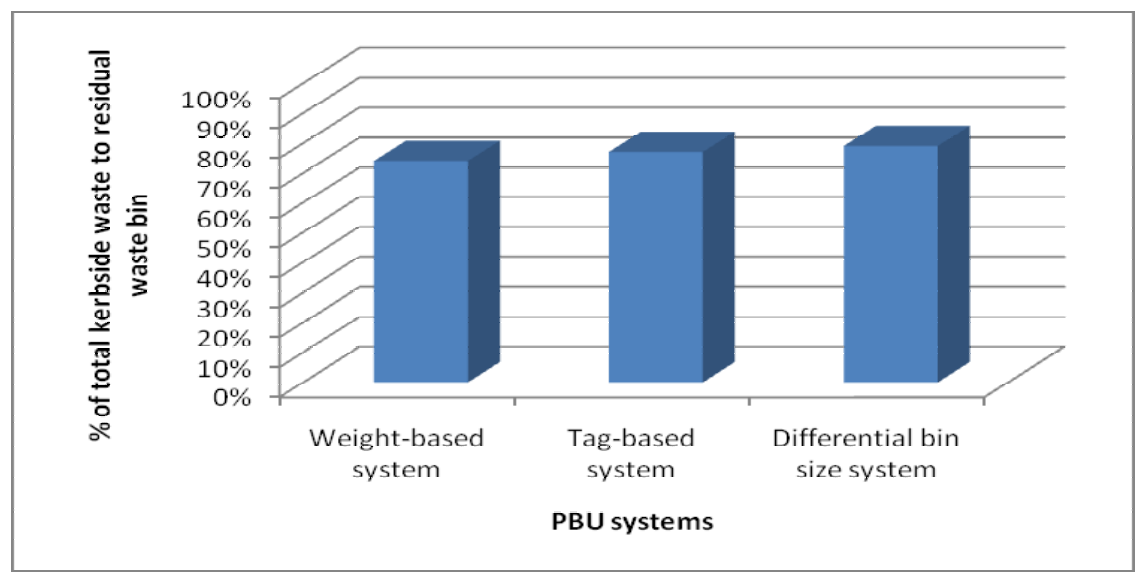

Figure 1: $\quad$ Percentage of total kerbside waste placed in the residual waste bin under the three PBU systems in use.

\subsubsection{Kerbside recycling collection}

The data showed that households using a weight-based charging system had a slightly higher rate of recycling than households in either tag-based charging systems or differential bin size systems, with an average of $24 \%$, to an average of $21 \%$ for the tag based collectors and differential bin size collectors.

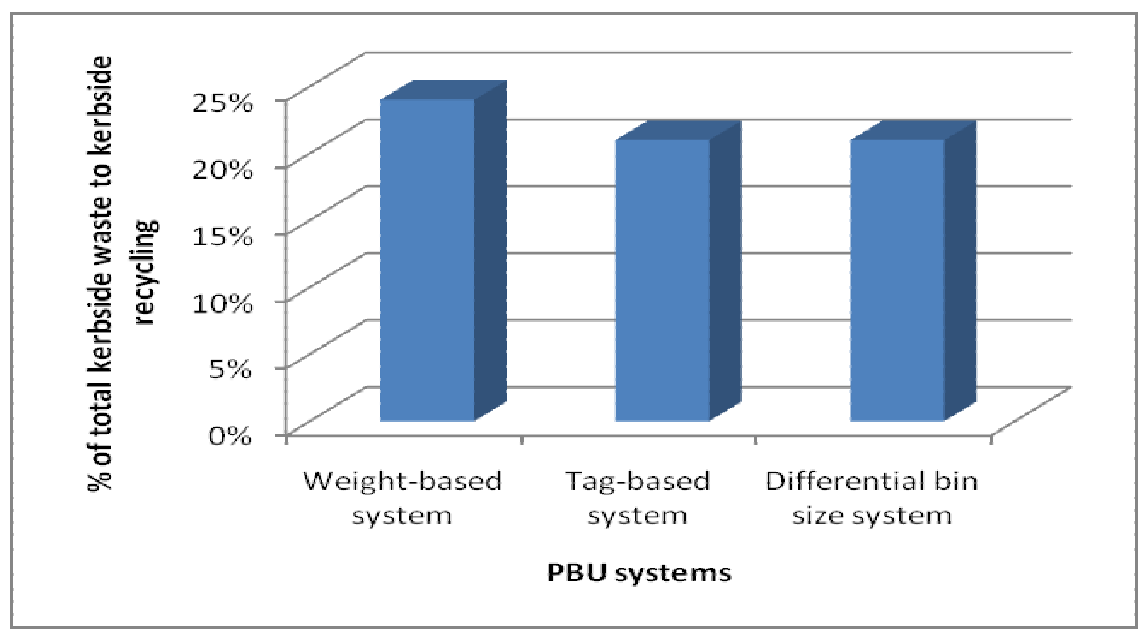

Figure 2: $\quad$ Percentage of total kerbside waste placed in the recyclables bin under the three PBU systems in use. 


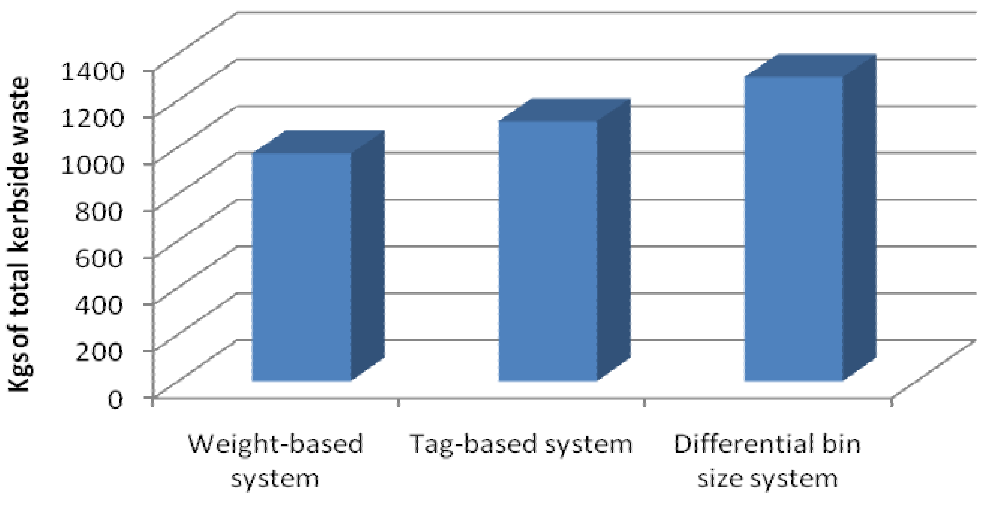

PBU systems

Figure 3: Kilogrammes of total kerbside waste under the three PBU systems.

\subsubsection{Total waste presented at kerbside}

The average weight-based household presents less waste at the kerbside in total than the average household using tag-based or differential bin size charges. The average figures were $972 \mathrm{~kg}$ (weight-based), 1,153kg (tag-based) and $1,299 \mathrm{~kg}$ (differential bin).

However the 'per kilogramme' form of weight-based charging is the most effective system in terms of kerbside recycling and total waste figures, with 'banded weight' and 'average weight' systems experiencing less success with the 'average weight' system prompting figures similar to tag-based and differential bin size charges when the three weight-based systems are considered separately.

In addition to analyzing all collectors together within their PBU system grouping local authority data and private collector data were considered separately; finding that weight-based systems are the most effective PBU systems environmentally, followed by tag-based systems, with differential bin size charging the least environmentally effective of the three. Table 1 summarizes the findings on the three PBU systems.

Table 1: $\quad$ Comparing PBU systems using average figures per household.

\begin{tabular}{|l|c|c|c|}
\hline & Disposal & Recycling & Total Waste \\
\hline Weight Based & $74 \%$ & $24 \%$ & $972 \mathrm{~kg}$ \\
\hline Tag based & $77 \%$ & $21 \%$ & $1,110 \mathrm{~kg}$ \\
\hline Differential & $79 \%$ & $21 \%$ & $1,299 \mathrm{~kg}$ \\
\hline
\end{tabular}

\subsection{Conclusion}

As table 1 shows, weight-based charges are the most effective PBU system from an environmental perspective. These charges have prompted the highest 
diversion rates from landfill and the lowest total kerbside waste figures. Households with a weight-based system also present the least waste at the kerbside.

Weight-based charges can be considered preferable on the whole from the point of view of the environment. However the this form of charging only produces slightly higher recycling rates and slightly lower waste to landfill rates than the other PBU systems used. When the three forms of weight-based charging are considered separately we see that the 'per kilogramme' form of weight-based charging is the most effective system, with 'banded weight' and 'average weight' systems experiencing less success and the 'average weight' system prompting figures similar to tag-based and differential bin size charges. In light of this finding the research concludes that the most environmentally sustainable PBU system is the 'per kilogramme' weight-based charge.

\section{References}

[1] Department of the Environment, Heritage and Local Government. Waste Management: Changing Our Ways. DoEHLG, Dublin, p.11 1998a.

[2] Department of the Environment, Heritage and Local Government. An Action Plan for the Millennium. DoEHLG, Dublin, 1998b.

[3] Linderhof, V., Kooreman, P., Allers, M. \& Wiersma, D. 'Weight-based pricing in the collection of household waste: the Oostzaan case' Resource and Energy Economics 23(4), 359-371, 2001.

[4] Nestor, D. V. \& Podolsky, M.J. 'Assessing incentive-based environmental policies for reducing household waste disposal', Contemporary Economic Policy 16(4), 401-411, 1998.

[5] Department of the Environment, Heritage and Local Government, Press release "Cullen announces nationwide move to pay-by-use waste charges". DoEHLG Press Office. Dublin, 2004c.

[6] Lawlor, J \& Scott, S (1996) Environmental Services. In: The Fiscal System and the Polluter Pays Principle: A Case Study of Ireland, eds Barrett, A, Scott, S, \& Lawlor, J. Ashgate, Aldershot. 1997.

[7] Department of the Environment, Heritage and Local Government. Sustainable Development - A Strategy for Ireland. DoEHLG, Dublin, 1997a.

[8] Department of the Environment, Heritage and Local Government. An Action Plan for the Millennium. DoEHLG, Dublin, 1997b.

[9] Department of the Environment, Heritage and Local Government. Preventing and Recycling Waste: Delivering Change. DoEHLG, Dublin, 2002.

[10] Department of the Environment, Heritage and Local Government. National Overview of Waste Management Plans. DoEHLG, Dublin, 2004a.

[11] Department of the Environment, Heritage and Local Government. Waste Management - Taking Stock and Moving Forward. DoEHLG, Dublin, 2004b. 
[12] European Economic Community. Council Directive 75/442/EEC of 15 July 1975 on waste. European Economic Community, Brussels, 1975.

[13] European Economic Community. Council Resolution of 24 February 1997 on a Community strategy for waste management. European Economic Community, Brussels, 1997.

[14] O'Callaghan-Platt, A. \& Davies, A. A nationwide review of pay-by-use domestic waste collection charging in Ireland: extensive survey findings. An interim report for the EPA, Dublin, EPA, 1-93, 2007.

[15] Dijkgraaf, E. \& Gradus, R. 'Cost Savings in Unit-Based Pricing of Household Waste - The Case of the Netherlands', Resource and Energy Economics 26(4): 353-371, 2004.

[16] Sterner, T. \& Bartlings H. 'Household waste management in a Swedish municipality: determinants of waste disposal, recycling and composting', Environmental and Resource Economics 12(4), 473-491, 1999.

[17] Bauer, S. \& Miranda, M. L. 'The urban performance of unit pricing: An analysis of variable rates for residential garbage collection in urban areas' Report prepared for U.S. Environmental Protection Agency, Washington, D.C. 1996.

[18] Dunne, L. Weighing up benefits of paying for waste collection by the kilo. The Irish Times. 26th January 2004 pp.12. Dublin, 2004.

[19] Dunne, L. An investigation into waste taxes and charges. University College Dublin, 2005.

[20] Fullerton, D. \& Kinnaman, T. C. 'Garbage, Recycling and Illicit Burning or Dumping', Journal of Environmental Economics and Management 29, issue 1: 78-91, 1995.

[21] Kinnaman, T. C. \& Fullerton, D. 'Garbage and Recycling with Endogenous Local Policy', Journal of Urban Economics 48: 419-442, 2000.

[22] Miranda, M. L. \& Aldy, J. E. 'Unit-Pricing of Residential Municipal Solid Waste: Lessons from nine case-study communities', Journal of Environmental Management 52: 79-93, 1998.

[23] Skumatz, L. Measuring Source Reduction: Pay as you Throw/ Variable Rates as an example. Washington, Skumatz Economic Research Associates, Inc. 2000. 